Article

\title{
A Monetary Measure of Inclusive Goods: The Concept of Deliberative Appraisal in the Context of Urban Agriculture
}

\author{
Saverio Miccoli ${ }^{1, *}$, Fabrizio Finucci ${ }^{2, \dagger}$ and Rocco Murro ${ }^{1, \dagger}$
}

1 Department of Architecture and Design (DIAP), University of Rome La Sapienza, P.zza Borghese 9, 00186 Rome, Italy; E-Mail: rocco.murro@uniroma1.it

2 Department of Architecture, University of Roma Tre, Via della Madonna dei Monti 40, 00184 Rome, Italy; E-Mail: fabrizio.finucci@uniroma3.it

$\dagger$ These authors contributed equally to this work.

* Author to whom correspondence should be addressed; E-Mail: saverio.miccoli@uniroma1.it; Tel.: +39-06-4991-8895; Fax: +39-06-4991-8894.

External Editor: Peter Newman

Received: 30 June 2014; in revised form: 23 October 2014 / Accepted: 1 December 2014 / Published: 5 December 2014

\begin{abstract}
In the major U.S. and European cities (e.g., Detroit, Seattle, San Francisco, London, Paris, etc.) that since 2007 have been feeling the effects of the international economic crisis, regeneration processes have been set up thanks, among other things, to the synergic impact generated by urban agriculture (UA). There are numerous and greatly varied effects, linked to localization, that are consistent with the paradigm of sustainable development, although the sporadic, spontaneous, and discontinued nature of UA conditions its capacity to strongly influence an entire community. With a view to enhancing the efficiency and effectiveness of urban agriculture, and to facilitating its planning, this study puts forward the implementation of an organized and multifunctional agro-urban system. The consent of the population involved is vital for the creation and implementation of the system, therefore ascertaining not only the existence but also the level of social appreciation of this resource is of paramount importance. With the aim of providing a suitable methodology for ascertaining the social appreciation of the stakeholders in the agro-urban system, the paper puts forward a deliberative monetary appraisal that combines an economic valuation based on hypothetic scenarios with direct, inclusive, and dialogic approaches. In this paper we present: (1) a general overview of the main characteristics of urban agriculture and related problems; (2) the principal methodological elements for defining and
\end{abstract}


planning an agro-urban system; and (3) guidelines for a deliberative appraisal procedure related to an agro-urban system.

Keywords: deliberative appraisal; inclusive goods; urban agriculture; community monetary valuation; sustainable cities

\section{Introduction: Urban Agriculture Sustainability as an Inclusive Good}

The recession that followed the international financial crisis affected many cities, but it was low-income communities that suffered the most. The recession produced a large variety of scars on urban areas: vast uncultivated urban expanses, abandoned or unused building envelopes, unsold or unfinished residential buildings, and scores of slums where redevelopment has not taken place. These portions of territory, and the social groups that inhabit them, are at the center of a new regeneration trend based on the effects of urban agriculture (UA).

According to the FAO, more than 130 million people in Africa and 230 million in Latin America grow gardens in urban areas [1]. In China, where every year $1 \%$ of agricultural land is lost, the agri-urban phenomenon is quite striking. For instance, the Beijing Municipal Administration has pledged to maintain at least 120 million hectares of farmland, and for a long time now peri-urban areas devoted to the production of foodstuffs have surrounded Shanghai [2].

In the United States, the country that is making the most of this new trend, these new forms of agriculture in urban areas are reshaping the geography, the landscape, the vitality, and the economic prospects of entire communities. In some areas, the supply of locally-produced food obtained from UA reaches extremely high levels - for example, $90 \%$ of the eggs and $60 \%$ of the vegetables consumed by the community [3]. In San Diego the Urban Agriculture Regulatory Summary Table regulates a variety of urban agricultural uses, including farmers' markets and urban farms [4]. Through the Urban Agriculture Program, the City of San Francisco manages 36 community gardens and more than 220 parks, for a total of over 4100 acres of land [5]. In New York, at present, there are over 1000 community gardens and more than 30 urban farms [6]. Detroit is completing its transition from an old "Fordist" center to a city that aspires to sustainable development through regeneration programs based on the exploitation of productive agricultural land vacated by demolition works. In Seattle, the P-Patch Program manages 81 community gardens on 2650 lots, for a total of over 12 acres used for agricultural production [7]. Chicago's South Side neighborhood is in the middle of a project that will transform the area into a large green belt for agricultural use; the initiative aims at transforming 13 square miles, in order to expand business and employment opportunities [8].

In Canada, community gardens are becoming increasingly popular as they contribute to the food security of certain social groups. Progressively, Montreal has developed an urban agriculture system based on community gardens: today there are over 6400 lots assigned for cultivation [9].

As regards the situation in Europe, in Spain, Portugal, Greece, and Italy, UA until now has been a rather contained, less structured albeit steadily growing phenomenon. In northern Europe, UA initiatives are mainly part of specific plans promoted by local institutions. 
In Italy, in recent decades, UA initiatives have mainly resulted in the creation of urban gardens. However, it should be said that cultivable urban farmland is becoming increasingly and consistently in demand; the greater initiatives mainly take place in large cities.

\subsection{Urban Agriculture: Definitions and Main Characteristics}

The economic-productive feature appears to have been a key element from the earliest definitions of UA; many cultural currents initially concurred on the definition of UA as a kind of economic activity related to the production of food and non-food products in intra-urban or peri-urban areas [10,11]. However, this first definition does not take into account distribution and disregards the advantages of the direct contact between supply and demand that results from agricultural activities in urban or peri-urban areas.

Subsequent definitions also included breeding and fish farming, and integrated the concept of production to distribution in the local area. According to these definitions, UA comprises the practice of farming, processing, and distributing food in and around villages, towns, or cities; it may also encompass animal husbandry, aquaculture, and horticulture [12]. The importance of the direct relationship between agricultural production and urban market demand translates into small and widespread production facilities that exploit localized economies instead of mass production and economies of scale.

At the same time, a definition of UA more related to sustainability emerged that included, for the agricultural activities taking place in urban areas, a cycle involving the use and return of human and material resources. Indeed, urban farming is defined as an agricultural activity localized within or at the edge of a city or a metropolis. It farms, processes, and distributes its products, using most of the resources available in the urban area in which it is located; at the same time it provides human resources, materials, and services for the same urban area [13].

The latter definition paved the way for the one currently used by the FAO. UA is an industry that produces, processes, and distributes food and fuel, responding to consumer demand from the urban context in which it is located; through the use of intensive production methods and the reuse of natural resources and waste, it includes the production of a variety of crops and livestock [14].

This definition, although commonly accepted, is considered incomplete as it lacks a social, environmental, cultural, and recreational vision. In the definition adopted by the Council for Agricultural Science and Technology (CAST), UA assumes the features of a multi-functional system, comprising a spectrum of traditional activities (production, processing, marketing, distribution, and consumption) and a multiplicity of benefits related to leisure, economic vitality, entrepreneurship, individual health, and general welfare within the community, as well as aesthetic, landscape, and environmental elements [15]. The interest in UA has finally turned towards environmental improvement and food security [16], which led to the "food justice" concept and the identification of UA as an element capable of guaranteeing this justice system, by granting access to healthy eating for all the stakeholders in a given community [17].

An important aspect to understand about the UA phenomenon has to do with certain features that distinguish it from traditional farming activities carried out in rural areas. Urban farms, as opposed to rural ones, can be mobile, temporary, and not directly tied to the land; indeed, alongside traditional techniques, soilless, hydroponic, aeroponic, or aquaponic methods are frequently used. 
In rural areas, farming is the main source of livelihood for families and entire communities; agricultural activities in urban areas, however, are, in general, a secondary aspect of the lives of individuals and do not constitute the main source of income but a part-time or complementary activity. As regards the profile of the community, whereas in rural areas most members are involved in agricultural activities, in the urban setting the community is involved in highly heterogeneous activities and this leads to very different social and economic structures and different positions on agriculture. Indeed, rural communities are inclined to recognize its importance and benefits, while in urban settings the positions and standpoints can be very diverse, contrasting, and conflicting.

In the urban context, capital gains, annuities, and competitiveness of non-agricultural land uses play an important role; contention regarding alternative uses, in fact, can disrupt the continuity of agricultural activities, thus reducing the sense of certainty of land use and affecting the propensity for investments and production. With regard to costs, in the case of rural agriculture the advantages derived from the intensive use of soil are based on economies of scale, which reduce production costs. Instead, in the case of UA, the main advantage derives from the proximity to the market, which translates into reduced transport costs; on the other hand, land fragmentation and small-size lots make it difficult to leverage economies of scale.

The Four Zone City Model [14] offers an effective example of the relationship between urban areas and typological features of UA. In this model it is quite clear that UA is strongly influenced by the density of settlement. The four zones in question in the urban area correspond to the following names: Core, Corridor, Wedge, and Periphery.

In the Core Zone, at the center of an urban area (characterized by high density and a greater variety of land uses), UA takes on particular forms such as roof gardens and crops cultivated on balconies, temporarily free plots, or areas destined for different uses (such as public parks, gardens, schools, etc.). In the Corridor Zone (similar to the Core Zone but with a lower degree of density), urban agricultural activities tend to be carried out along the main roads and railways with the production of ornamental horticulture, small pasture, greenhouse vegetables, flowers, poultry farms, and other small animal farms. The Wedge Zone, large areas that are not directly suitable for urban development, such as slopes, ravines, or wetlands, houses the activities described also for the previous areas, as well as the production of milk, eggs, fruit, and fish. In these areas UA plays a key role in environmental protection [16]. Many Wedge Zones are at risk of erosion, landslides, and flooding as these areas are exposed to too much pressure in the form of deforested slopes, unstable hills, etc. so UA, including reforestation and terracing, can improve the stability of slopes and help avoid future landslides and soil erosion [18]. Finally, the Periphery Zones, or the rural-urban edge, house small and medium-sized farms that aim at producing solely for the urban market; this is where intensive vegetable and fruit production mainly takes place — production is favored by more available land and easier access to the urban market.

By analyzing the relationships that are triggered between urban areas and agricultural activities, several studies have singled out three different territorial systems [19] presenting: (1) a diffused and dispersed urban matrix; (2) an urban matrix organized in poles and lines; and (3) a prevailing rural matrix. The first system is characterized by a continuous urban fabric interspersed with small non-adjoining agricultural areas. The agricultural production in these spaces is tied to three main factors; the plots are small, access to them is often difficult, and as they are found in built-up areas conflicts arise that are such as to limit their productive potential. These areas are dedicated to the cultivation of fruit and 
vegetables that are suitable for small spaces and direct marketing; there is strong competition between land allocated to agriculture and that allocated to construction and urban development as the latter leads to high land prices that penalize the residual agriculture. In the second system, it is possible to distinguish between the rural areas and urban fabric. Settlement is circumscribed in several poles and along lines; the rural areas maintain their production structure and the zones allocated to agriculture are continuous but are bounded by the expanding urban borders. The farms are diversified according to type of management and/or production; there are fruit and vegetable farms that are slightly larger than those in the previous system, found alongside various types of arable crop farms and animal breeding farms. Compared to the previous system, the areas of land allocated to agriculture are larger, the land prices are more affordable, and there is less conflict with the urban residents. The third and last territorial system presents a prevailing rural matrix and is characterized by settlements formed of small rural communities, with little tendency to expand, that gravitate round a major urban center. The allocation of large expanses of land to agriculture makes it possible to conserve natural and landscape elements. In this system, the farms are medium to large scale and run by professional farmers. Agricultural potential, also in terms of production capacity, can generate new opportunities for development if it is integrated with the urban system.

When speaking of new trends in city models, the term Smart City is often used. For some a city can be defined as smart when investments in human and social capital and traditional and modern communication infrastructure fuel sustainable economic development and a high quality of life, with a wise management of natural resources, through participatory action and engagement [20]. For others, the Smart City concept essentially means efficiency based on intelligent management, integrated ICTs, and active citizen participation [21]. In the Smart City, where resources are made available through an efficient infrastructure network based on an integrated and coordinated system of subsets (safety, information, water, health, infrastructures, economy, environment, etc.), UA, by ensuring healthy food, utilizing cultivation methods that are less aggressive to the environment, and fostering the creation of micro-economy, plays a key role.

\subsection{Economic, Environmental, and Social Effects of Urban Agriculture}

UA is a complex phenomenon that can contribute significantly to sustainable urban development [22]. From an economic perspective, urban agricultural activities can embrace very different productive sectors. In numerous cases, the use of efficient production strategies and specialization of high-quality crop plants generates high economic value from an urban farming perspective. The gross returns to producers from farmers' market sales are generally $200 \%-250 \%$ higher than sales to wholesalers/ distributors. In addition, at present, farmers earn $\$ 22$ for every $\$ 100$ spent by consumers, but with direct marketing methods, that amount can increase to $\$ 30$ [23].

The economic activity of an urban farm triggers several positive effects on the entire community. Employment improves both in terms of number of employees and in terms of the birth of working groups that later develop into business incubators, cooperatives, and other micro-production companies. Moreover, it boosts the attractiveness and the start-up potential of microenterprises indirectly related to the agricultural cycle. The improvement in general economic conditions produces an increase in consumption levels; access to local products at lower market prices, made possible by a shorter supply chain, increases the spending power and savings of the population. According to the Community Food 
Security Coalition, the community garden of Milwaukee enables families to save \$100-300 a year, while in Philadelphia this amount is around $\$ 700$ [16].

Finally, it is important to underline that the market values of properties that are located in neighborhoods upgraded by the actions of UA also improve. Some studies report that the presence of gardens raised property values by as much as $9.4 \%$ within five years of establishment [24]. Other studies pointed out that rents charged in areas immediately around the gardens are significantly higher than in the city as a whole. In the city of St. Louis, overall, median gross rents fell $\$ 4$ in 10 years; by contrast, the areas immediately surrounding the gardens saw a median increase in the Median Gross Rent of $\$ 91$ and an average increase of $\$ 113$ [25].

As far as the environment is concerned, the main effects of UA are the reduction of greenhouse gas emissions, energy saving, and, subsequently, a reduction of the contribution to global warming. The inclusion of "farm-to-table" food in the urban market reduces the consumption of products stored and distributed through energy-intensive and high-impact facilities and infrastructure. Agricultural activities can also cause the urban microclimate to change by regulating humidity, reducing wind action, providing natural shading, and contributing to $\mathrm{CO}_{2}$ emission reduction. A decisive contribution of UA to improving environmental quality comes from reusing urban waste products, in particular by recycling biodegradable waste to create compost and reusing filtered rainwater and wastewater from urban drains for irrigation purposes. The new agricultural and urban water cycle, together with reforestation activities and terracing, contributes to land hydrogeological reclamation; the hydrology of the urban setting is also improved by the maintenance of numerous permeable areas. Finally, many urban areas are reconverted due to the tendency of UA to reuse empty, abandoned, or poorly utilized areas, e.g., fallow and interstitial lands become manicured green spaces that are accessible, aesthetically pleasing, and much appreciated by the community.

At a social level, it must first be said that UA offers the public, particularly poor households, access to fresh foods, with positive effects on health and quality of life. With the income from the newly generated agricultural work or savings thanks to access to less expensive supply, the disposable income of families on the verge of poverty increases. In communities affected by the economic crisis, UA improves the psychological profile of individuals through food security guaranteed to families and the acquisition of skills in a new field of employment. These activities are also a tool to reinsert the disadvantaged into society.

UA supports and strengthens the sense of belonging to the community. The new living model in neighborhoods fosters social interaction between groups of different ethnic, socio-economic, and generational backgrounds. The common protection objectives also have a direct effect on reducing the crime rate and increasing a common civic sense.

\subsection{Study Objectives}

The positive impact of UA can be maximized if the activities are organized in a multifunctional system that enhances their efficiency and efficacy from an environmental, social, and economic point of view. To achieve this objective, and with the aim of facilitating the regulatory matters and planning of UA, this paper provides methodological guidelines for the implementation of a multifunctional 
agro-urban system by pointing out the issues linked to the relationship between the various stakeholders and suggesting the main intervention policies necessary for the suitable planning of the system.

To ensure the efficacy of the system, the tools used for its planning must be agreed upon and approved directly by the community in question and the social appreciation that the community shows towards this resource must be revealed. The aim of this paper, therefore, is to specify the key operative elements of an evaluation method that makes it possible to detect the existence and the extent of the social appreciation of an agro-urban system. The method is based on the preferences directly expressed by the members of the community in question and by means of a course of action based on inclusion, information, dialogue, negotiation, and communication.

\section{Planning Urban Agriculture: Key Methodological Elements}

With rare exceptions, traditional urban planning has neglected aspects of agricultural production in envisaging local changes and rarely has it considered food production [26] due to, among other things, an approach based on the strict separation between urban and rural issues. In the past few decades, however, the boundary between urban and rural has been slowly fading and the displacement of some food production in peri-urban areas has contributed to undermining other established features in the relationship between the urban setting and the countryside. In addition, global environmental awareness has put the spotlight on some critical aspects of the industrial agriculture production model. Indeed, industrial-scale agriculture has proven to be subject to diminishing and economically unsustainable margins and returns in the long term [27,28]; in addition, the increased production of traditional agriculture, necessary to meet the future demand for food, leads to a sharp increase in the consumption of finite resources.

Therefore, producing enough food resources in the urban environment with low-impact, short chain agriculture has become one of the most important challenges for future urban sustainability. The issue of food production and distribution will have to be dealt with by policy makers, planners, and programmers in the urban areas. The disciplines that deal with the transformation processes in the city should offer solutions to regulate, evaluate, and plan activities targeted at converting parts of the city while advocating a new balance between urban growth and the preservation of agricultural areas.

With the aim of facilitating the planning, implementation, and management of UA, we are proposing an urban agriculture model designed as a system that we call Agro-Urban System (AUS). UA, which by nature is sporadic, spontaneous, and discontinuous, makes a decisive contribution to sustainable urban development, a contribution that could be strengthened if the elements of UA were to be organized in a system.

From an economic viewpoint, systematization makes it possible to pursue objectives regarding economic efficiency by exploiting economies of scale, as well as organizational efficiency; it is possible to obtain permissions, comply with regulations, and have access to forms of funding that otherwise would not be granted. Furthermore, by exploiting the principle of complementarity, it is possible to generate added value from the aggregation of heterogeneous resources. The organizational structure of a system fosters the exchange of information and resources, enhancement in terms of both quantity and quality of the offer, and a more effective promotion of the goods produced. 
From a town planning and environmental viewpoint, a series of elements organized in a system can assume the form of an ecological network that translates into a better safeguard of available habitats, thus contributing to the conservation of biodiversity. It is also possible to create continuity between productive green areas that become structural elements in the layout of the city. The system allows for integrated planning and management of the territory such that it is possible to share regulations and ways of utilizing urban agricultural areas. This encourages the reduction of certain negative effects linked to agricultural activities (e.g., by limiting the use of pesticides and strictly regulating high-impact and polluting practices).

Lastly, from a social point of view, a system is usually the result of cooperation based on similarity, reciprocity, and the persistence of shared values. A set of elements organized in a system lends itself to planning and open management in a community context - capable, therefore, of strengthening the sense of belonging to a community, creating new communities, and increasing existing social capital. If organized in a system, UA can become the driving force behind a sustainable lifestyle capable of creating new living conditions and quality of life.

The Agro-Urban System (AUS) we propose can be defined as a set of interconnected agricultural and urban elements that behaves as a whole according to general rules, where each element contributes to the common goal of sustainable development. This system is characterized by different, organized, and coordinated areas that tend to produce an overall balance. To maximize the efficiency and effectiveness of an AUS, it has to be multifunctional, where agricultural areas integrate urban uses and functions, while urban areas integrate agricultural uses and functions [29]. For example, the function related to the agricultural market can be located in urban areas; at the same time, an agricultural area can accommodate some urban green functions by integrating the food production system with the cultural or recreational functions of green spaces. The agricultural activity must relate to the urban context where it is inserted; it must take into account that the resulting system is, at the same time, a place of production, a target market, a source of income, and an area where people live. Likewise, urban activities must relate to the characteristics of agricultural production activities in order to share certain elements (urban services, infrastructures, lines of mobility, etc.).

The training and deployment of an AUS is strongly connected with the presence of vacant land [30] in the area and with the relationships established between the three main stakeholders involved-the owners of the vacant land, the farmers, or those who are willing to start and invest in agricultural activities, and the rest of the community. The relationship between these subjects and the expectations they have regarding the utilization of the vacant land are at the root of several issues to be addressed for the success of an AUS.

For the owners of vacant lands, agricultural use is in direct competition with more profitable alternative uses, many of which are linked to construction and land development (Agricultural uses vs. Alternative uses); some authors call this phenomenon "Pressure from Increasing Land Prices" [31]. Some owners, because of the more profitable uses, are unwilling to give their land to potential farmers, hence the system may lack available land.

International case studies offer partial solutions to this problem: (1) where spontaneous activities occurred that were, however, limited in size and ability to positively impact on the urban area; (2) in some contexts (e.g., Seattle), the administration played a key role in looking to foster agreements between farmers and owners; and (3) finally, other cities (e.g., San Diego and San Francisco) decided to 
solve the problem through urban planning which contemplates agro-urban land uses. This approach is effective only in the face of transparent, consensus-based programming mechanisms and bottom-up planning able to proactively resolve any conflicts between owners and decision makers.

Another issue is the relationship between available land and the degree of suitability of agricultural land in urban areas, in terms of location, size, physical-chemical soil composition, and accessibility to the necessary resources (Available Land $v s$. Suitable Land). Unlike rural areas, in urban areas there is a risk that new projects, buildings, or plans will alter access to the resources needed for cultivation, nullifying the initial investment. The land may also be contaminated because of previous activities; in such cases, if and when requalification activities are too costly, the land may be used for the production of species unrelated with the food chain or crops that can accumulate contaminants in the non-edible parts; in other cases, the solution lies in soilless or raised bed crops. In order to avoid a waste of resources, it is advisable to verify the suitability of the land through valuation methods that are commonly used in rural areas, whereas in urban areas these methods must implement mechanisms for evaluating agricultural land for which future urban transformation is contemplated.

Another element that may hinder the implementation of an AUS is how the rest of the community, i.e., members of the community not involved in agricultural activities (neither as farmers nor as owners), perceive UA. If uninformed about the effects of UA they could prefer traditional green urban uses (cultural, recreational and sports facilities, etc.) to agricultural uses, in particular in the peripheral areas of the city, often lacking quality green spaces (Agricultural uses vs. Alternative Green Uses). Socio-cultural biases are decisive; one of these is the "modern view of the city" that makes citizens perceive UA as rural, not modern, with low economic returns, unproductive, inappropriate, and contrary to the beautiful, clean, efficient city ideal [14].

If the community perceives the benefits as being the exclusive advantage of farmers and owners, this could result in a lack of consensus about agricultural activities and UA could lack the market it needs for its sustenance. The absence of information and greater awareness of the role played by agricultural activities in the involved community could cause a shortage in the elements required for the operation of a AUS, which would thus lack the land to be devoted to cultivation and the demand from urban markets to which the produce should be sold. Setting up an AUS requires, therefore, a high level of consensus on the part of the community.

The balance between agricultural use and alternative green use can be attained only through informed, participatory decision-making involving the community in which the desirable scenario must be shared and accepted. Only in this way can conditions be met to satisfy producers, i.e., farmers who find it convenient to start the business, and consumers, i.e., individuals who are aware of the benefits arising from the consumption of UA produce. The future of the AUS and its ability to produce positive direct effects for both producers and consumers depend on the market equilibrium between these two entities. Moreover, a range of integrated (social, environmental, and economic) effects would be generated for the entire community (community effects).

The relationship between the stakeholders and the issues to be addressed for the success of an AUS are outlined in Figure 1. 
Figure 1. The agro-urban system: a relational diagram of stakeholders.

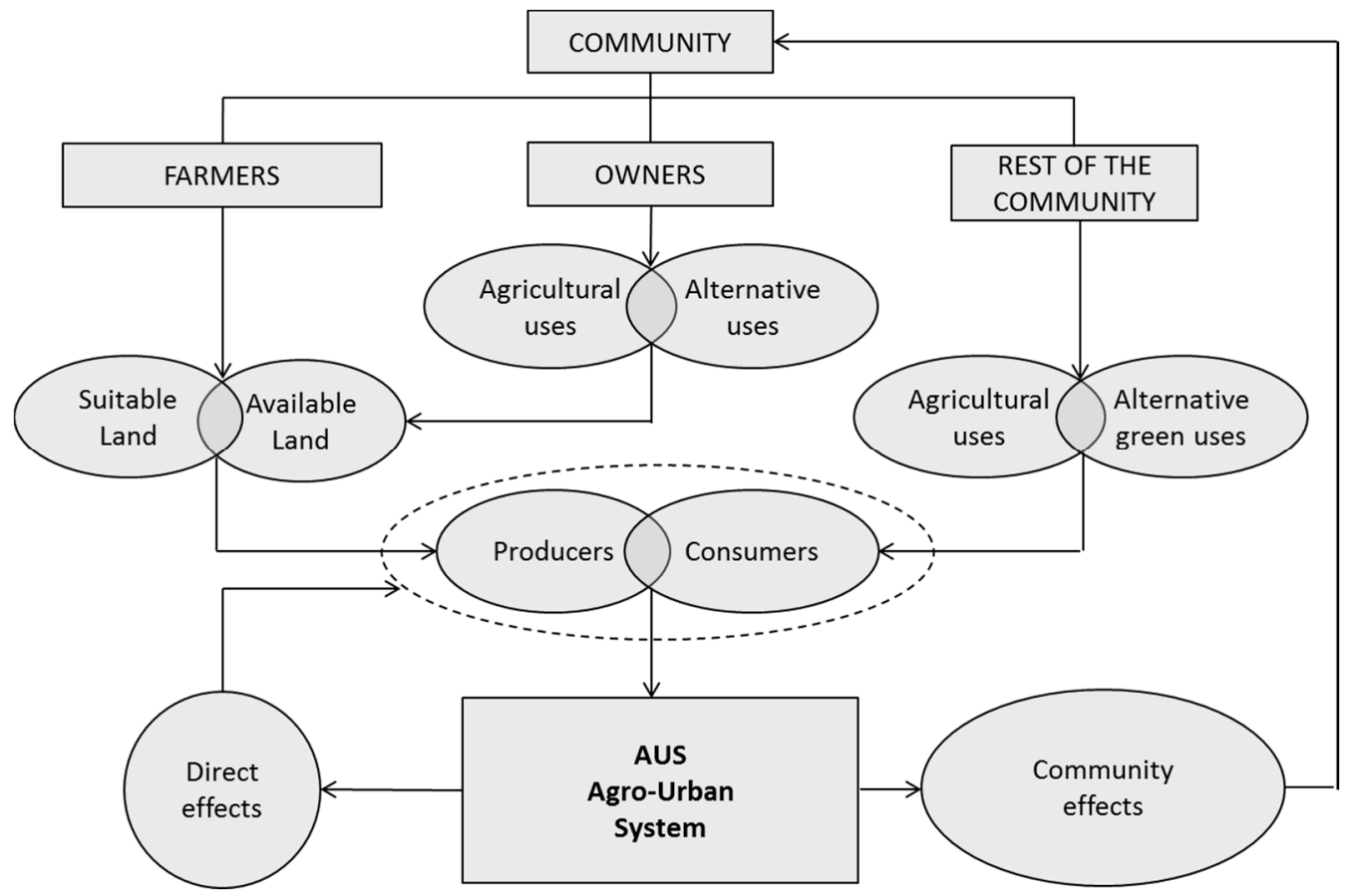

Considering the above-mentioned issues, strategic urban planning (in particular long term and large scale) aimed at the implementation of an AUS will focus on the creative regeneration of the territory, integrating both natural and agricultural components into the urban context. It must provide an alternative - if only for purely food and environmental needs - because of the urban development processes of recent decades, in particular in those areas characterized by the uncontrolled and fragmented extension of cities into natural and rural areas (as in Italy) producing - through progressive trespassing - land consumption, landscape hybridization, and pulverized settlements, as well as settlement hierarchy and identity annihilation.

To this end, planning on an urban scale will have to specify the permissible forms of UA in the AUS and define the modalities for the establishment of necessary infrastructure and the location of the new functions. It will also have to provide for the most suitable ways to identify and make land available, and to regulate the areas devoted to different UA forms by suggesting suitable activities for each single area. Lastly, it will define the regulatory standards that apply to each individual element involved in the AUS. The planning of the system will allow the introduction of an "agro-urban standard" in terms of minimum provision of cultivable space per capita. Future planning of an AUS will have to gather its strengths and envisage solutions capable of meeting the public interest, redefining urban shapes and margins, redeveloping empty and unused areas for environmental purposes, and applying compatible densification, stratification, and replacement actions to current assets.

In order to counter those development approaches that incorporate and overbuild vast stretches of farmland, drafting comprehensive, integrated local system development programs targeted at farming in the city is not enough. It is crucial that each policy instrument used for these purposes - taking into account its relevance and social inclusiveness - be shared, approved, and supported by the communities that it affects directly. Nevertheless, to obtain a more reliable degree of significance, social involvement 
should no longer be expressed through economic functions and established through political representation, but rather defined according to preferences expressed directly by the members of the community.

\section{Deliberative Appraisal: A Monetary Measure of Social Appreciation}

To accomplish an economically sustainable AUS, the points of view of both the public sector and the private sector are necessary but in themselves not sufficient. Further efforts should be made to restore the community directly involved to their key role.

This condition, based on the impact environmental issues have had in many international contexts, can be met also in the urban farming sector, currently but especially in its future perspective. However, being aware of a trend in favor of implementing major UA programs does not preclude assessing the potential social considerations of the matter. When urban planning is well aware of its regulatory function, it cannot continue to assume that every decision taken will automatically translate into successful implementation; it must, rather, be able to predict the social impacts of the agreed direction. Before expressing the ordinary economic judgments, in term of value or choice, in planning a program targeted at creating an AUS, it would be useful to know if and to what extent the members of the community approve a resource of this kind.

Seen as a tool to achieve sustainable development, an AUS must take into consideration many factors related to the environment. These are crucial elements to improve the quality of life of both today's and tomorrow's generations in the short to medium term, and-more importantly - the long term. Hence, it is necessary to keep these factors in mind to comprehensively evaluate the importance society gives to an AUS, the extent of which, therefore, not only depends on the possible uses of the good (direct and indirect, present and future, actual and potential), but also on the presence of characteristics that are not related to use. Humankind finds the latter characteristics in the intrinsic properties of a good, and points at them through its preferences.

From a valuation perspective, the interesting economic aspect here is the esteem value deriving from the importance that the evaluating subjects are willing to give the AUS, which is considered separately from other resources and in the light of the quality being objectively recognized. In short, the formulation of the esteem value must consider the assessment of the social perception in terms of the effects produced by a combination of three orders of causality: (a) utility factors; (b) intrinsic or existence factors; and (c) factors of scarcity, due to naturally limited goods or goods of limited availability due to high costs (if producible) and market prices (if tradable).

As regards the extent of social appreciation of an AUS, it should be noted that there are least three reasons to recommend the use of the monetary scale or in any case its use to complement other assessment methods. The first is linked not only to the possibility to verify the existence of a preference but also to quantify its extent. Monetization is the way that reflects with greater clarity and immediacy the relevance of each expressed preference and the sensitivity exerted by the resource at hand on each involved member of the community. The second is that through monetary expression, it is easier to communicate and make people understand the importance of an AUS, especially if it is significantly extensive. Any other type of argument would be less effective for citizens, bureaucrats, and politicians alike, who, on matters relating to goods of high public value, are now more accustomed to reasoning and deciding in terms of monetary costs and benefits. The third reason is that the monetary value of a good 
of social interest, such as the AUS, is a useful reference for determining the amounts of any public investment or shares of it, to determine the issuance of bonds or the introduction of purpose taxes, or to make comparisons in view of alternative uses of available funds.

In short, in evaluating an AUS, the monetary measurement unit provides greater advantages in the formulation of economic judgments, both in terms of value and choice. Even if such judgments were to lack a certain degree of precision, they would be preferred because of better understanding and utilization. The following text describes the guidelines for a monetary valuation procedure by which the members of a community involved in the implementation of an AUS directly assess its social appreciation through a direct, inclusive, and discursive approach.

\subsection{Inclusive Approaches to Valuation}

In practicing direct democracy, for several decades many countries have initiated integrative forms of community involvement in the various stages of the public decision-making process. Participatory democracy and deliberative democracy are the most important cultural proposals in the reform processes involving the more mature representative democracies. In many cases, the inclusion process involving citizens in policy-making processes started upon the direct and explicit pressure of local communities who did not recognize themselves in the choices made by their decision-makers. In other situations, inclusion was the result of long cultural renewal processes also promoted directly by local communities. Slowly a new way of thinking about the role of the citizen in democratic life is consolidating through forms of active involvement in relevant public issues; citizens are no longer the receiving end of the decision-making process but are full protagonists in the underlying debate.

Because of the recent escalation of social tension, conflict, and disagreement with many public decisions concerning the transformation of territory, community participation is now considered a useful tool to manage and bring together all the interests at stake, combining local community development and protection in view of sustainable choices. To this end, transparent and inclusive processes are activated in a bid to make the community participate in a process the aim of which is to build consensus, leading to a successful transformation and full support from the public [32].

Inclusive approaches enshrine democratic value because they ensure that the subjects involved (and their interests) have a right to expression and the ability to influence and shape the public choice [33]. A strategic value adds up to a democratic one, since a public option built according to the principles of inclusive approaches is shared, less conflicting, and stands a good chance of succeeding.

Many studies based on surveys [34,35] have highlighted that in Western democracies, traditional political participation is stable or decreasing while other forms of democratic participation, even unconventional ones, are increasing [36,37]. Since the 1990s, citizens have increasingly distanced themselves from political parties; they are more critical towards public institutions and less positively oriented towards governments [37]. The use of inclusive practices is largely fostered by the crisis that representative democracy is going through, and with it the representation system.

The inclusive methods proposed by international scenarios can be classified on the basis of the share of power transferred from the institutional decision-maker to the participatory context. There are procedures that merely disseminate information among the public, others that activate further community consultation, some that seek the cooperation of the entire participatory set in order to define 
scenarios and identify solutions, and still others that entrust citizens with decision-making. In any case they all pursue the goal of attaining democratic, transparent, and accountable choices.

The theoretical and methodological framework of the valuation discipline has long attempted to internalize the contribution obtained from the participatory processes. In many cases, measurement approaches that reflected the point of view of the community were accomplished. For example, the Goal Achievement Matrix [38] made it possible not only to ascertain if and how an alternative design would be capable of pursuing a set of criteria, but also by which social groups it would have been considered beneficial. Even the Community Impact Valuation, developed on the Planning Balance Sheet paradigm [39], provided decision-making support by highlighting the impacts of various alternatives on the social sectors concerned.

The participatory processes, based on the direct involvement of citizens in decision-making, can provide the basis for a theoretical and evolved operational assessment in tune with citizens' common sentiment [40]. Indeed, citizens are on the one hand aware of increasingly critical situations produced by traditional forms of representative democracy and, on the other, in favor of a broad introduction of direct democratic instruments that in many ways seem more appropriate to reflect socially the relationship between means and common goals [40].

In the latest practice, deliberative procedures, based on assemblies, groups, or citizen juries, are consolidating. These procedures are based on the concept of deliberative democracy, which differs from the concept of democracy as an aggregation of preferences. In this regard, deliberative decisions must be taken by all participants without resorting to a vote. The most innovative aspect is the importance given to the transformation of votes in the course of a discursive process oriented to the definition of the public good, through which the preferences assumed in the initial phase are transformed by taking into account the point of view of others [41]. Through debate, participants in the deliberation discuss the matters in hand with one another until they reach shared decisions. The aim of the resolution is to enable individuals to make decisions in full awareness of the general interest. The debate directs the identity and interests of citizens in ways that contribute to the construction of the public good [42].

Although developed in the 1970s, it was not until the 1990s that deliberative procedures were applied first in Germany, then in the UK, the USA, and Australia. Among the various deliberative-type techniques developed over the years, open assembly models [43] and "mini-publics" [44] stand out. The former intends to stimulate maximum inclusiveness and representation in terms of the point of view of the more concerned citizens; the latter seeks statistical representation through random or stratified samples that reflect the main characteristics of the target population. In the former case, the goal is to ascertain how citizens are swayed to form decisions in conditions allowing for an informed debate. As regards the assembly models, the deliberative element is less important, since the meetings serve the purpose of "civil learning spaces" [45]. As far as mini-publics are concerned, the quality of the discussion correlates with the amount of information to which citizens are exposed in the deliberative context, as well as their chances to interview witnesses and subject-matter experts, and their ability to reason on the experience and perspective of their fellow citizens. In general, communication quality is affected negatively by the size of the meeting [46,47]; the larger it is, the harder it is to come to true deliberation.

In the complex processes that govern social valuation of an AUS, the mini-public paradigms are preferable to open assembly models as these can prevent the participation of those who already have 
power and resources (wealth, social prestige, numbers, and aggregation power). Consequently, it is possible to encourage the inclusion of those groups with the greatest difficulty to organize themselves collectively or those less endowed with material resources and political power.

The valuation procedures applied to deliberative participation processes enable the members in communities involved in an AUS to express value judgments based on informed relationship, dialogue, negotiation, and communication with stakeholders. This leads to a gradual reduction in conflict, as members outline emerging profiles of balance between strong stakeholders and the often-voiceless supporters of the common good.

\subsection{Valuation Method and Technique}

In order to evaluate an AUS, the solution offered here is a deliberative appraisal procedure that combines the deliberative processes with Stated Preference Methods (SPM), approaches to the valuation of economic goods based on individual behaviors related to hypothetical scenarios. In the proposed procedure, monetary valuation must be preceded by a discourse-based decision $[48,49]$ involving a random sample of the community involved in the AUS. The sample is required to express a preference as regards the value attributed to an AUS based on informed and rational choices; individuals in the sample highlight their opinions, discuss them, and possibly change them after they have been debated.

Through a series of meetings, the group members are provided with the necessary information to discuss and formulate the social appreciation of an AUS; they must also be given the opportunity to interview witnesses and discuss issues with each other under the supervision of expert moderators. The expressed value is therefore the result of a process of insight and debate in which the participants shall include information and request further clarification from stakeholders, witnesses, subject-matter experts, or other people whom they may consider appropriate to involve. The Deliberative Appraisal procedure shapes a socially representative group of the citizens involved in an AUS capable of having a longer term, better informed, and impartial vision on important matters concerning the system; the opinions and interest perceived by the participants should reflect those of the represented citizenship. As compared to conventional monetary valuation approaches, the Deliberative Appraisal model results in an assessment that gives more social legitimacy to the outcome, is less prone to cognitive biases, and is at the same time related to the formation of collective identity.

The Willingness to Pay (WTP) in conventional SPMs is expressed through a questionnaire administered by e-mail, phone, or in person; in the latter two cases, respondents are given the opportunity to request clarification or additional information only from the interviewer and only during the interview (usually not longer than $45 \mathrm{~min}$ ). The preferences of the respondents, based on the opinions and interests received up to the time of the questionnaire, are expressed through an individual WTP. The total value of the good is obtained through the aggregation of individual WTPs as established during the investigation.

The Deliberative Appraisal of an AUS, however, is aimed at forming a WTP shared by the evaluation group. Participants assess the system as citizens belonging to a community and, over the course of deliberation, identify a set of shared values and a common identity to be protected, thanks to a sense of interdependence and belonging that develops within the group.

The identification of shared values and the formation of a common identity are the prerequisites for the implementation of an AUS. It is possible to envisage a successful AUS only through the recognition 
of its quality, its benefits, and all the other elements by the community as a whole, as only the members of the community together can account for its social importance.

From an operational perspective, in the first phase each member of the random sample of the community can compare his/her views with those of others so if they wish, after gaining more knowledge and understanding of the positions and interests of the community, they can change their original opinions (Figure 2).

Figure 2. Deliberative Appraisal: diagram of the informative and deliberative phase.

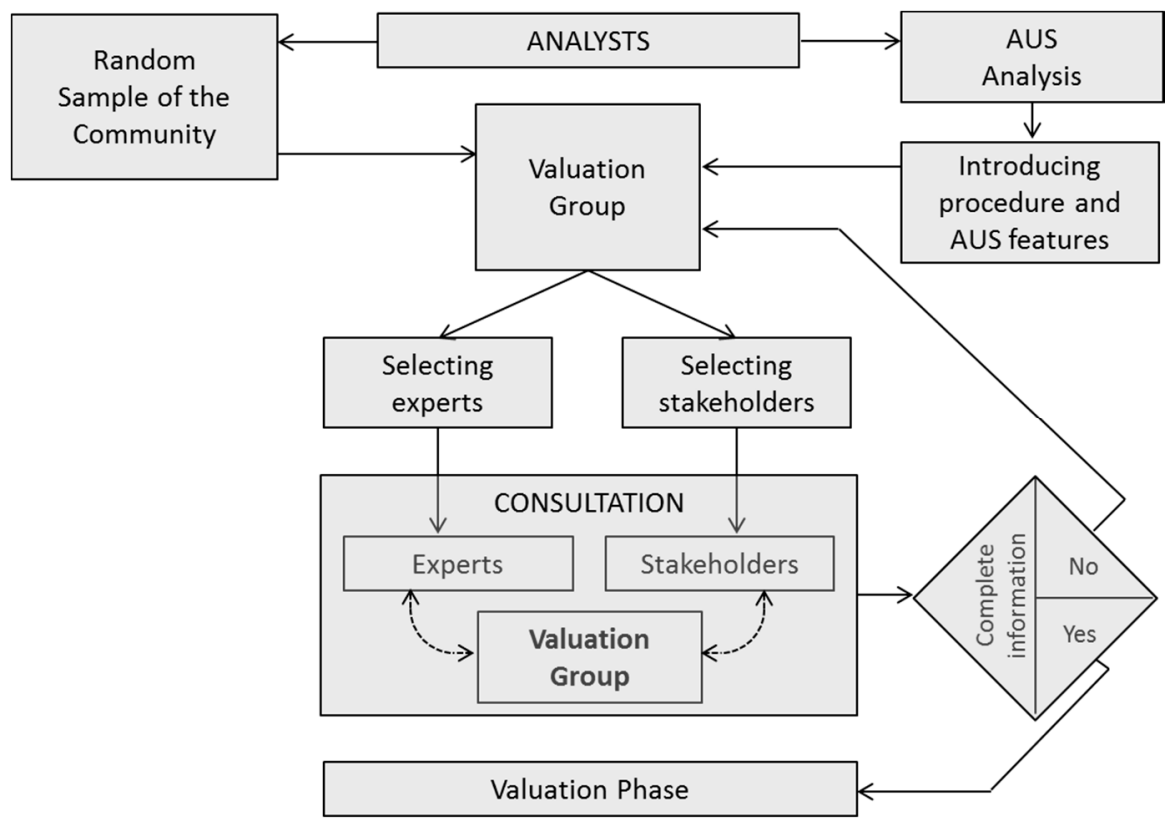

After the participants have received the most important information regarding the process of valuation and the characteristics of the AUS from the analysts, the valuation group compiles a list for consultation by both the experts and the stakeholders. During the consultation phase, the experts and stakeholders are at the disposal of the valuation group to provide further knowledge, clear up any doubts, and specify the positions and points of view of the various actors involved. The experts answer any questions regarding environmental, social, and economic problems linked to the implementation of the AUS and provide the valuation group with an in-depth explanation of the effects of agriculture in an urban setting, comprising criticality factors and potential. They also reveal the socio-cultural biases where UA is concerned, an intervention that renders this problem surmountable.

The stakeholders outline expectations, concerns, and interests to the valuation group. Following their intervention, the intentions of the public decision-makers and the positions of the owners of the areas in question, the firms operating in the agricultural sector, the farmers of today and potentially of tomorrow, and any other actors directly involved in the AUS and possibly in conflict with agro-urban activities become clear. If the information gained by the valuation group is considered to be exhaustive, the process enters the valuation phase; on the other hand, further talks are organized if necessary with further information provided by new experts or new stakeholders.

In the valuation phase, during a Deliberative Session, the participants attempt to come to an agreement on the matter of a shared WTP that expresses the social appreciation of the AUS (Figure 3). 
Figure 3. Deliberative Appraisal: diagram of the valuation phase.

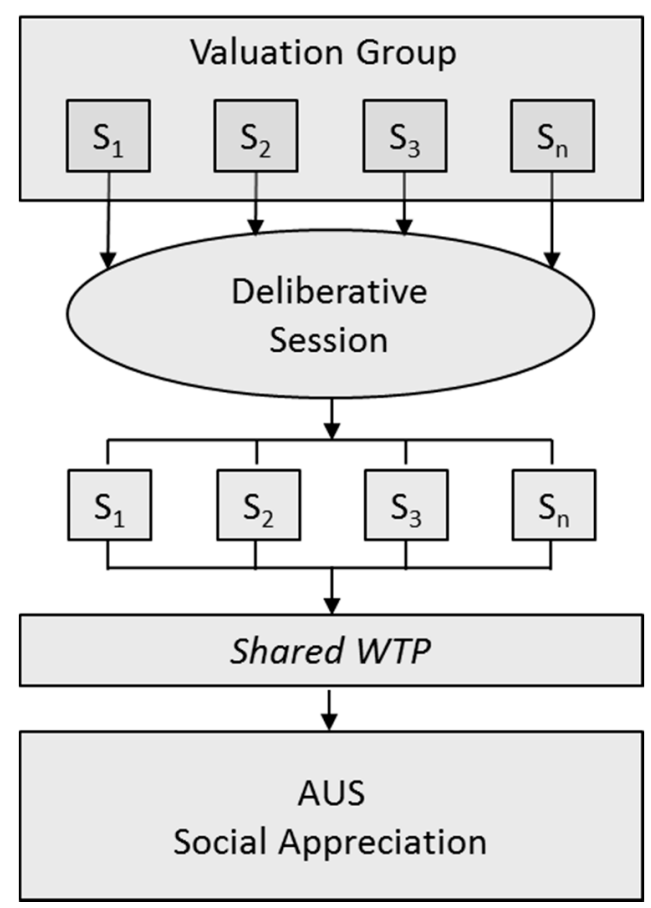

The members of the group are not asked to give a personal assessment but a value to be attributed to the good in view of the general interest. The total value, in this case, is not the sum of individual interests. The agreement evolves through the rules of the dialogue [50], in the conviction that dialogue is a motivating force that can resolve conflicts through shared social understanding [51]. Therefore, a key role is attributed to rhetoric, seen as a tool to bring together different positions on the basis of more persuasive arguments and, in deliberative contexts, often referred to as bridging rhetoric [52]. In the pursuit of a shared WTP for an AUS, reference is made to a deliberative process based on small groups (such as Citizens Juries and Consensus Conferences), in order to achieve the effects of a "psychological group" [53] and come to an agreement on the value attributable to the good.

When Deliberative Appraisal is based on a small group, the use of types of SPMs that require complex statistics is not recommended. In fact, due to the limited number of observations that are drawn from the participants, reliable and statistically significant results cannot be obtained. By contrast, the use of open-ended and iterative bidding versions of the contingent valuation method may trigger an interactive and iterative process to define a shared WTP, which takes into account the agreement reached by the group.

\section{Conclusions}

During the delicate programming steps of an AUS, the role played by the community involved in recognizing the quality, benefits, and other elements that globally allow for a monetary valuation of the social importance of the system is a crucial factor. By means of the social appreciation of the AUS expressed by the community, it is possible to verify the existence of the main fundamental requirements for its implementation.

The active involvement of citizens and a debate based on appropriate information allow the deliberative process to produce a responsible, democratic, and shared decision-making process. Inclusion gives a new role to citizens; through individual growth, achieved during the deliberative 
process, citizens become responsible actors in the decisions to be made, capable of carrying out useful tasks for the community. On the other hand, the principles of sustainable urban development themselves impose the transformation of social relationships towards democracy and promote a different notion of the value of civic engagement in local policies, with the identification of economic, social, and environmental conditions capable of favoring the full citizenship of the various social groups [54].

Deliberation and the formation of consensus, which differ from the aggregation of individual preferences, are an appropriate path to follow for a monetary assessment of an agro-urban system intended to be a resource of collective interest. Often individuals do not have well-defined preference as regards social goods, as they still have to build them for themselves [55]. While standard SPMs tend to detect pre-existing preferences, deliberative processes, through discussions and argumentation, allow individuals to assign shared monetary values to the AUS.

Only through widespread and growing experimental activity will it be possible to improve the validity of deliberative economic assessment procedures. The difficulty of achieving this, and the level of control required, should not discourage their use. A deliberative evaluative experimentalism, by innovating ways in which citizens can take part in civic life, makes public choices more democratic, enhances the value of citizen self-determination, and provides a means of measuring the estimated value a community assigns to social goods or projects.

Although these types of procedures are perceived as an additional burden weighing on slow and confused decision-making processes, there is a conviction that they may represent virtuous paths in public choice fulfillments and a cost for which democratic administrations could find it convenient to plan. This would prevent top-down decisions, which often generate conflicts, from producing much heavier social, economic, and political impacts. While waiting expectantly for the re-legitimization of the political and social representation of citizens' interests and identities, it is our duty to explore public decision-making processes capable of involving the least advantaged members of society [56] in making choices that fulfill the needs, preferences, and desires expressed by the community. The Deliberative Appraisal is functional in pursuit of this objective.

\section{Author Contributions}

The authors contributed equally to this work.

\section{Conflicts of Interest}

The authors declare no conflict of interest.

\section{References and Notes}

1. Food and Agriculture Organization of the United Nations. Available online: http://www.fao.org/ urban-agriculture/en (accessed on 5 September 2013).

2. Girardet, H. Urban agriculture and sustainable urban development. In CPULS: Continuous Productive Urban Landscapes-Designing Urban Agriculture for Sustainable Cities; Viljoen, A., Ed.; Elsevier: Amsterdam, The Netherlands, 2005.

3. Bhatt, V.; Farah, L.M. Designing edible landscapes. Open House Int. 2009, 34, 5-7. 
4. The City of San Diego, America's Finest City. Available online: http://www.sandiego.gov (accessed on 25 August 2013).

5. Urban Agriculture Program. Available online: http://sfrecpark.org/park-improvements/urbanagriculture-program-citywide/ (accessed on 25 August 2013).

6. Community Gardens Program. Available online: http://www.agriculture.ny.gov/cg/cghome.html (accessed on 25 August 2013).

7. P-Patch Community Gardens. Available online: http://www.seattle.gov/neighborhoods/ppatch/ aboutPpatch.htm (accessed on 25 August 2013)

8. Chicago's urban farm district could be the biggest in the nation. Available online: http://grist.org/food/chicago-urban-ag-farm-district-could-be-the-biggest-in-the-nation/ (accessed on 25 August 2013).

9. Montreal's Community Gardening Program. Available online: http://ville.montreal.qc.ca (accessed on 25 August 2013).

10. Mougeot, L.J.A. Introduction: an improving domestic and international environment for African urban agriculture. Afr. Urban Q. 1996, 11, 137-152.

11. Quon, S. Planning for urban agriculture: A review of tools and strategies for urban planners. Available online: http://www.international-food-safety.com (accessed on 30 August 2013).

12. Bailkey, M.; Nasr, J. From Brownfields to Greenfields: Producing Food in North American Cities; United Nations Development Programme: New York, NY, USA, 1999.

13. Mougeot, L.J.A. Urban agriculture: Definition, presence, potentials and risks, main policy challenges. In Proceedings of International Workshop on Growing Cities Growing Food: Urban Agriculture on the Policy Agenda, La Habana, Cuba, 11-15 October 1999.

14. Smit, J.; Ratta, A.; Nasr, J. Urban Agriculture: Food, Jobs, and Sustainable Cities; United Nations Development Programme (UNDP): New York, NY, USA, 1996.

15. Butler, L.; Moronek, D.M. Urban and Agriculture Communities: Opportunities for Common Ground; Council for Agricultural Science and Technology: Ames, LA, USA, 2002.

16. Brown, K.H.; Carter, A. Urban Agriculture and Community Food Security in the United States: Farming from the City Center to the Urban Fringe; Urban Agriculture Committee of the Community Food Security Coalition: Portland, OR, USA, 2003.

17. Alkon, A.; Norgaard, K. Breaking the Food Chains: An Investigation of Food Justice Activism. Sociol. Inq. 2009, 79, 289-305.

18. Beatley, T. Green Urbanism: Learning from European Cities; Island Press: Washington, DC, USA, 2000.

19. Lardon, S. Organisation spatiale des exploitations agricoles dans des territoires locaux. In Acteurs et Territoires Locaux. Vers une Géoagronomie de L'aménagement; Benoît, M., Deffontaines, J.P., Lardon, S., Eds.; Editions INRA: Versailles, France, 2006. (In France)

20. Caragliu, A.; del Bo, C.; Nijkamp, P. Smart cities in Europe. J. Urban Technol. 2011, 18, 65-82.

21. Seisdedos, G. Qué es una Smart City? Available online: http://www.coit.es/publicaciones/bit/ bit188/monograficoseisdedos.pdf (accessed on 23 October 2014). (In Spanish)

22. Lovell, S.T. Multifunctional Urban Agriculture for Sustainable Land Use Planning in the United States. Sustainability 2010, 2, 2499-2522. 
23. Abel, J. Extension's Role with Farmers' Markets: Working with Farmers, Consumers, and Communities. Available online: http://www.joe.org/joe/2012february/iw3.php. (accessed on 23 October 2014)

24. Been, V.; Voicu, I. The Effect of Community Gardens on Neighboring Property Values. Real Estate Econ. 2008, 36, 241-283.

25. Liu, J. Gateway Greening. Available online: http://actrees.org/files/Research/gateway_greening whitmire.pdf (accessed on 30 August 2013).

26. Pothukuchi, K.; Kaufman, J.L. The Food System. A Stranger to the Planning Field. J. Am. Plan. Assoc. 2000, 66, 113-124.

27. Georgescu-Roegen, N. Energia e Miti Economici; Bollati Boringhieri: Torino, Italy, 1998. (In Italian)

28. Agricultural produce grown on an industrial scale stands out for an excessive waste of embodied energy. As a matter of fact, from 7 to 10 calories of energy from non-renewable energy sources are needed for every calorie of food consumed.

29. Miccoli, S.; Finucci, F.; Murro, R. Toward Integrated Urban Agricolture Systems: Economic and Valuation Aspects. 2013, unpublished work.

30. Vacant Land: Land with no houses, offices, or other permanent structures. Vacant land maybe available for development, or it may set aside by a governments or a private owner to remain vacant. Fralex Financial Dictionary, 2012.

31. Priorr, A. Food and farming. In Peri-urbanisation in Europe: Towards a European Policy to Sustain Urban-Rural Futures; Piorr, A., Ravetz, J., Tosics, I., Eds.; Forest and Landscape University of Copenhagen: Frederiksberg, Denmark, 2011.

32. Miccoli, S.; Finucci, F.; Murro, R. Evaluation-Sharing in Landscape Enhancement. In Dynamics of Land Values and Agricultural Policies; Crescimanno, M., Casini, L., Galati, A., Eds.; Medimond International Proceedings: Bologna, Italy, 2013.

33. Miccoli, S.; Finucci, F.; Murro, R. A direct deliberative evaluation procedure to choosing project for Via Giulia in Rome. Pollack Periodica 2014, in press.

34. Putnam, R. Capitale Sociale e Individualismo; Il Mulino: Bologna, Italy, 2004.

35. Torcal, M.; Montero, J.R. Political Disaffection in Contemporary Democracies; Routeledge: London, UK, 2006.

36. Norris, P. The Democratic Phoenix; Cambridge University Press: Cambridge, UK, 2002.

37. Dalton, R.J. Democratic Challenger, Democratic Choices: The Erosion of Political Support in Advanced Industrial Democracies; Oxford University Press: Oxford, UK, 2004.

38. Hill, M. Planning for Multiple Objectives; Regional Science Research Institute: Philadelphia, PA, USA, 1973.

39. Lichfield, N. Community Impact Evaluation; Cambridge University Press: Cambridge, UK, 1996.

40. Miccoli, S.; Finucci, F.; Murro, R. Community participation and green infrastructures: A deliberative evaluation method. In Proceedings of First International Academic Conference Places and Technologies 2014, Belgrade, Serbia, 3-4 April 2014.

41. Miller, D. Deliberative democracy and social choice. Polit. Stud. 1991, 40, 54-67.

42. Cohen, J. Deliberation and democratic legitimacy. In The Good Polity. Normative Analysis of the State; Hamlin, A., Pettit, P., Eds.; Wiley-Blackwell: Hoboken, NJ, USA, 1989. 
43. Thematic Assemblies, Advisory Committees and Participatory Strategic Plans are mentioned by way of example.

44. Among the minipublic models, one can make a distinction between those based on small groups (a number comprised between 10 and 25 participants), such as the Ned Crosby's Citizen Juries in the United States, the Plannungszelle in Germany and the Consensus Conferences in Denmark, and others allowing the involvement of larger samples of the population, such as the XXI Century Town Meeting, Open Spaces Technology and Deliberative Opinion Poll by James Fishkin, bringing together several hundreds of people in order to find out what would be the public opinion if citizens had the opportunity to discuss and study a given subject.

45. Della Porta, D. Democrazie; Il Mulino: Bologna, Italy, 2011.

46. Parkinson, J. Legitimacy problems in deliberative democracy. Polit. Stud. 2003, doi:10.1111/ 1467-9248.00419.

47. According to Parkinson, beyond a very small number of participants, the resolution is lost in endless debating-replacing the conversation-and rhetorical appeals that replace the better-pondered arguments.

48. Lo, A.Y.; Spash, C.L. Deliberative Monetary Valuation: In search of a democratic and value plural approach to environmental policy. J. Econ. Surv. 2013, doi:10.1111/j.1467-6419.2011.00718.x.

49. Wilson, M.A.; Howarth, R.B. Discourse-based valuation of ecosystem services: Establishing fair outcomes through group deliberation. Ecol. Econ. 2002, 41, 431-443.

50. Habermas, J. Theorie des kommunikativen Handelns; Suhrkamp: Frankfurt a.M., Germany, 1981.

51. Warren, M.E. The self in discursive democracy, In The Cambridge Companion to Habermas; White, S.K., Ed.; Cambridge University Press: Cambridge, UK, 1995.

52. Dryzek, J.S. Rhetoric in democracy: A systemic appreciation. Polit. Theory 2010, doi:10.1177/ 0090591709359596.

53. A psychological group is defined as a numerically reduced set of people interacting and creating a bond of some sort. Within the group, they create a unified synthesis (Sintality) and a shift from individual to feel the feelings of the group (Weness).

54. Vicari Haddock, S.; Molaert, F. Rigenerare la Città: Pratiche di Innovazione Sociale Nelle Città Europee; Il Mulino: Bologna, Italy, 2009. (In Italian)

55. Sagoff, M. Aggregation and deliberation in valuing environmental public goods: A look beyond contingent pricing. Ecol. Econ. 1998, 24, 213-230.

56. Rawls, J. A Theory of Justice; Harvard University Press: Cambridge, MA, USA, 1971.

(C) 2014 by the authors; licensee MDPI, Basel, Switzerland. This article is an open access article distributed under the terms and conditions of the Creative Commons Attribution license (http://creativecommons.org/licenses/by/4.0/). 